\title{
The use of Whatsapp in today's mobile language teaching and learning
}

\author{
Karen Ferreira-Meyers ${ }^{1, *}$, and Joana Martins ${ }^{2}$ \\ ${ }^{1}$ Institute of Distance Education, University of Eswatini, Private Bag 4, Kwaluseni, Eswatini \\ ${ }^{2}$ Independent researcher, Póvoa de Varzim, Porto, Portugal
}

\begin{abstract}
This paper discusses the advantages and disadvantages of ICTs in the teaching and learning of foreign languages, in particular the use of WhatsApp in the Certificate in Portuguese programme offered by the Institute of Distance Education of the University of Eswatini. Theoretical aspects will be combined with practical examples of what has been happening on the WhatsApp platform since 2013 with learners of Portuguese. The practical part comes from field research undertaken by the tutor as a direct observer of activities and feedback between lecturers, tutors and students. The impact of COVID19 on the use of WhatsApp will also be looked at briefly. In conclusion, it will be noted that WhatsApp is a valuable environment to ensure that teaching and learning continues beyond the classroom and can be an important motivator for lifelong learning.
\end{abstract}

\section{Introduction}

This paper seeks to give an insight into recent developments in the teaching and learning of Portuguese as a Foreign Language in the context of the kingdom of Eswatini (Southern Africa). It shows the results of a desktop review of existing literature on mobile learning applications in the field of language teaching and learning in general and of Portuguese as a Foreign Language in particular, on the one hand. On the other hand, it explicits field research done with tutors and learners in the Certificate of Portuguese blended learning programme offered by the Institute of Distance Education of the University of Eswatini. Before concluding, the authors also briefly look at how the COVID19 pandemic has impacted on the use of WhatsApp.

\section{Whatsapp: advantages and disadvantages}

The pedagogical benefits of WhatsApp have been defended by many researchers, such as [1]. Below we present some advantages and challenges of using WhatsApp for the pedagogical purpose, based on the studies by [2], adapted by [3] and based on our own experience.

\footnotetext{
${ }^{*}$ Corresponding author: karenferreirameyers@gmail.com
} 
It is a discussion tool as WhatsApp provides a suitable environment for discussing the most varied topics. The teacher / mediator can propose different themes / problems to involve the learners in the discussion or to think / gather ideas on any subject. You can start in the classroom and then extend to WhatsApp after class with the whole class or form groups, or you can start the discussion on WhatsApp and continue in the classroom. WhatsApp can be used as a task/activity feedback tool and tool for academic guidance: with WhatsApp it is much simpler and faster for the teacher to give feedback on jobs because it is possible to send voice messages and mark all aspects of the correction or even simply because it allows contact the student at any time and place without having to wait for the next class.

WhatsApp allows synchronous and asynchronous interactions. WhatsApp can be used to produce and disseminate educational videos and podcasts. Another benefit is the possibility of viewing the video or listening to the podcast as many times as the learner wants/needs.

Many of the themes presented in class can be contextualized with images from the real world / authentic material. Sometimes in class it is not possible to use relevant authentic material to answer all the questions that arise, but with WhatsApp sharing is done easily and quickly.

Cooperation between peers can be promoted by the possibility of sharing content and supporting material, for example: research articles, e-books, laws, YouTube channels, links, etc. WhatsApp can also be used for data collection since the teacher / researcher / student researcher can use this medium to send voice or written questions and receive answers in the same environment, thus promoting quick feedback.

In addition, WhatsApp not only promotes cooperation, since everyone is producing their own material for sharing in the group, but it also promotes collaboration, as knowledge is being created by a group through discussion in shared construction. It can be used as a tool to assess student participation: The teacher / moderator can use WhatsApp groups as a means to assess student participation. WhatsApp is also ideal to motivate and stimulate students: It is very important in the teaching-learning process to involve students so that they reach the objectives defined by the curriculum and their own objectives. Through WhatsApp, students can feel more comfortable than during face-to-face classes to ask questions or share interests, even when talking about contexts with large classes $(+/-50$ students) it is much easier for the teacher to evaluate the participation of students and reward them throughout the process than limit this to a test / exam grade.

As a mobile learning tool, WhatsApp also affords higher forms of inclusion: learners are all different, some are more extroverted and others are more introverted, some have visual and other hearing problems; in any case, WhatsApp allows more introverted students to feel more comfortable participating, those who express themselves better through the written channel feel more confident, those who have visual limitations can access the material through voice messages or those who have hearing problems can read all content and upload a video that can be translated by a sign interpreter. Attention deficit students also benefit from this tool since they can read or hear the information, stop or move forward, repeat as many times as they wish.

In this particular study, the most important benefit of WhatsApp is that it can be seen as a language learning tool: The idea that a language is not learned simply by studying grammar and vocabulary is increasingly widespread. It is through the practice of the language that the learner develops his language skills. When using the grammatical content and vocabulary learned in the production of sentences and in an attempt to dialogue, this is when the learning process becomes really significant. WhatsApp is a very useful tool for practicing writing, listening and speaking skills. The teacher can ask the student to send 
voice messages and evaluate their pronunciation or help the student with the articulation of some sounds and words when sending voice messages and their explanation in writing.

\section{Teaching and learning of Portuguese at the University of Eswatini}

The Portuguese language arrived in the Kingdom when the first Lusophone speakers immigrated. In 1969 there was already an operational Portuguese school, located on the premises of the Portuguese club in the capital city. It closed down around 1974, and reopened on a smaller scale a few years later, briefly. Home schooling and intergenerational transmission of language skills has occurred since those first days of the presence of Portuguese nationals. Over the years, families requested formal classes for their children and as soon as 1998 classes were introduced in selected schools, one of which is Sifundzani High School (located in Mbabane, the capital city), where Portuguese has been taught since that year [4]. While the main mandate of the Alliance Française is to teach French, there is provision in its statutes to encourage intercultural exchange and thus Portuguese was also introduced, in addition to French and siSwati, as a teaching and learning subject. The Department of Modern Languages of the University of Swaziland (which changed its name to University of Eswatini in June 2018 to follow the country's general name change announced by King Mswati III on 19 April 2018) thought it useful to add a Portuguese section to the existing French section at the beginning of the new millennium. This translated in the design and implementation of a Certificate in Portuguese programme for which classes started in 2009 [4].

The certificate in Portuguese is a blended learning programme that has been developing Moodle as the main learning management system for years now, although due to the lack of infrastructural support, attitude, preferences, availability of technology and internet connection, among other factors it's not being used. IDE certificate in Portuguese didn't find any alternative to Moodle and as the same constrains would also happen with any other LMS the alternative was to develop channels of communication that were already being used in daily lives of teachers and students. WhatsApp has been tested for years now in several educational contexts as it's been proved to be very beneficial not only to develop a community of inquiry but also a very helpful tool for language learning. For the past five years the certificate in Portuguese has been trying to adapt WhatsApp to students and teachers' needs and trying to take the most advantage of this tool. As a blended learning programme, the Portuguese certificate has been running smoothly despite malfunctioning of LMS Moodle. At this point in time it is believed Moodle would be very beneficial to improve the teaching learning of Portuguese as would also be of great help to have better bandwidth that would allow students to check eBooks, do some gamification to complement their study in a ludic way, but the context of Eswatini is not the same as of a developed country and suitable alternatives had to been found. It is stated by stakeholders that working in contexts like the one in Eswatini demands much more creativity and focused energy to teach and learn as the use of technology to enhance the teaching-learning process is much more limited.

The circumstances of the IDE certificate in Portuguese have just had a bigger challenge to face with COVID 19 arriving in the country. Suddenly the blended learning programme had to be taken fully online. WhatsApp being the most effective tool so far to complement face to face classes has now to be extended to replace this gap. There's not much more teachers can do in the circumstances faced as bandwidth is a problem, internet is expensive, not all students have a tablet or iPad or laptop, many of them are still learning ICT competences, but they all have a phone and use WhatsApp. 
It has been defended by many researchers for the past years the many advantages of WhatsApp with many case studies showing how efficient it can be. [5-6] examined the use of mobile devices in a language learning context. The results showed that the students evaluated educational materials designed for mobile phones very positively. The researchers also found mobile devices very effective for vocabulary learning. The results showed that EFL learners preferred using their phones because of easy access to materials and the ability to practice anytime, anywhere [7]. Lately WhatsApp developed WhatsApp which web is a feature that generating a QR code makes it possible for users to use it directly at any device making it easier to upload or download files, scan and join a group, create bigger groups and managing them. WhatsApp has been offering more and more features since it was developed in such a way that is making it useful for education in a very intuitive way (Fig. 1). We would like to see it integrating for example Moodle or Blackboard in a near future. WhatsApp business is now a reality so we believe integration with educative tools may not be so far away.

Besides all possibilities discussed above for WhatsApp we feel that having a guideline to develop classes would be much beneficial for teachers/ instructors/ mediators. Our approach at the certificate of Portuguese is to adapt 25 engaging and useful classroom activities for language learners using WhatsApp by [8] who is the Senior Consultant for Oxford University Press, Mexico. As well as being a teacher and teacher trainer, he is also the co-author of several series, many of which are published by OUP.

\section{COVID19: Impact of the pandemic on the teaching and learning of Portuguese}

The pandemic has greatly disrupted teaching and learning in Eswatini. Universities were closed in March 2020, at least physically, meaning that no students or staff were allowed on campus and all face-to-face learning was thus stopped completely. As March 2020 was in the middle of the second semester, students were already used to working on the WhatsApp platform, it was hoped that the switch to online learning would run smoothly, especially as, in line with [9]'s study results, students' attitude towards the use of WhatsApp for learning and teaching is generally positive, and earlier on already strategic thinking about online teaching and learning had been started [10].

However, this was not really the case. Learners soon noted a number of obstacles to the finalising of assignments and continuation of learning. Some students had this to say: "we are weary and scared of online learning as sessions seem to be based on time out sequences" (the student was referring to synchronous sessions). Students, because of the lockdown, were unable to get to internet cafés or get additional data or airtime because of financial constraints. Even though the coordinator, lecturers and tutors kept on encouraging students to continue interacting and learning (for example, by sending resources, asking questions and providing additional reading) the fear and stress related to the coronavirus spread made it difficult for students to participate meaningfully. Also, as [11] noted in their paper, both staff and students need to be trained effectively in order to assist each other on so-called social media. 


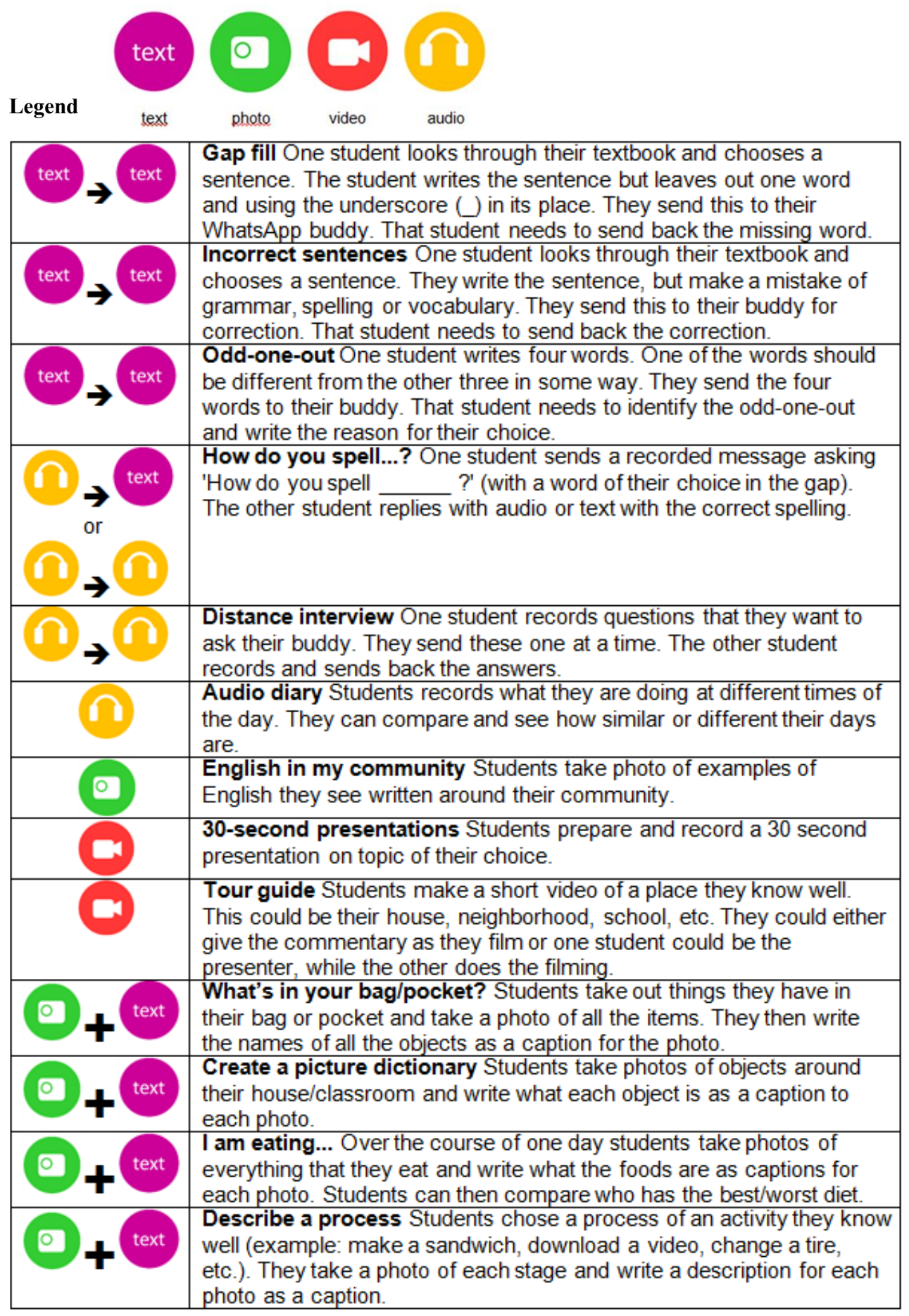

Fig. 1. Features of WhatsApp for teaching and learning 


\section{Conclusions}

The research undertaken combined an extended desktop review and other qualitative work in the form of questionnaires, interviews and focus groups in view of finding out whether learners and teachers (tutors) welcome interactions beyond the classroom on a mobile tool like WhatsApp, whether these interactions were useful and assisted in the teaching-learning process and, finally, whether they had an impact on motivation and learning on the whole.

Clearly, the answers to the above-noted research questions are positive. Learners are happy to interact via WhatsApp and quickly start using the target language for these interactions. The tutors enjoyed the interactions on WhatsApp and felt they were able to give additional punctual guidance to the learners (learning taking on place wherever and at any time - almost).

It is noted that the tutors felt it would be even more motivating on their side if there could be some form of remuneration for these additional teaching tasks. All in all, WhatsApp is a very useful resource for teaching, learning and practicing a language for many reasons, as noted above. For example, it is possible to access old recordings at any time in case of doubt or simply to use WhatsApp as a mobile support tool for cognitive assessment of the learner's evolution by the learning him/herself or by any other stakeholder.

WhatsApp is an important tool to allow instructors and learners to interact on a regular - if possible daily - basis. Language learning in particular needs such regular interaction for new skills to be acquired and already integrated skills to be practised. The COVID19 pandemic has shown us that more is needed to encourage, to nurture and to interact with learners. We have not looked at the specific needs to the instructors. This should also be done in further research.

\section{Acknowledgments}

The authors would like to thank all stakeholders involved, in particular the tutors and the learners who participated in the research that led to this presentation.

\section{References}

1. J. Bottentuit, O. Albuquerque, C. Coutinho, Revista Educaonline. 10, 67-68 (2016)

2. D. Bouhnik, M. Deshen, Journal of Information Technology Education: Research. 13, 217-231 (2014)

3. J. Junior, O. Albuquerque, Anais do I Simpósio Nacional de Tecnologias Digitais na Educação. UFMA-21, 22 e 23 de novembro - (2016)

4. M. Morais, K. Ferreira-Meyers, J. Martins, Lusoconf 2018. I encontro de língua Portuguesa e Relações Lusófonas: Livro de Atas, 308-317 (2018)

5. G. Stockwell, ReCALL. 19(2), 105-120 (2007)

6. P. Thornton, C. Houser, Journal of Computer Assisted Learning. 21, 217-228 (2005)

7. C.H. Chen, Journal of Educational Research. 102, 65-75 (2008)

8. Ph. Haines, https://oupeltglobalblog.com/2016/05/17/25-ideas-for-using-whatsappwith-english-language-students/ (2016)

9. E.S.D. Damanik, Journal Vision. 15 (2), 13-22 (2019)

10. K. Ferreira-Meyers, Strategic alliances for online learning within the Department of Modern Languages (University of Swaziland) (2010).

11. A. Oriji, F. Onikpa, European Scientific Journal. 15 (4), 15-39 (2019) 